\title{
Semi-2D modeling of river morphological changes caused by exceptional flooding
}

\author{
Tew-Fik Mahdi* \\ Polytchnique de Montreal, Department of Civil, Geological and Mining.C.P.6097, Succ. Centre-Ville, \\ Montréal, Québec, H3C 3A7. Canada
}

\begin{abstract}
This paper presents the application of the model, MHYSER 1.0 (Model for the HYdraulics of SEdiments in Rivers, version 1.0), to study river morphological changes due to exceptional flooding. MHYSER 1.0 is a semi-two-dimensional model using the stream tubes concept to achieve lateral variations of velocity, flow stresses and sediment transport rate. Each stream tube has the same conveyance as the other ones. In MHYSER 1.0, the uncoupled approach is used to solve the set of conservation equations'. After the backwater calculation, the river is divided in a finite number of stream tubes of equal conveyances. The sediment routing and bed adjustments calculations are accomplished separately along each stream tube taking into account lateral mass exchanges. MHYSER 1.0 is applied to the Ha! Ha! River (Quebec, Canada), a tributary of the Saguenay River, for the 1996 "downpour". The results show good correlation of with collected data. This application shows the capabilities of this model and predicts its promising role in solving complex real engineering cases.
\end{abstract}

\section{Introduction}

Precipitation-runoff floods and dam failure floods result in an unusual rapid water surface elevation, and high velocity outflow through the downstream river. The inundation of river banks may cause significant erosions, important landslides and creates potentially unstable embankments, as those observed in the aftermath of the Saguenay floods in 1996 [1].

This paper presents the model, MHYSER 1.0, Model for the HYdraulics of SEdiments in Rivers, version $\underline{1.0},[2,3,4]$. Following the presentation of MHYSER 1.0, a reach of the Ha! Ha! River (Quebec, Canada), a tributary of the Saguenay River, is described and used as a test case to demonstrate the capabilities of the MHYSER 1.0.

The parameters used in this research, especially Manning coefficient, are based on literature equations. Since the exercise is to demonstrate the capabilities of MHYSER 1.0 to capture morphological changes, the calibration of the model was not performed. Please note that an automated tool, OPTIMHYSER, is available to calibrate automatically any river model based on MHYSER 1.0 [5].

\footnotetext{
* Corresponding author: Tewfik.Mahdi@polymtl.ca
} 


\section{Overview of MHYSER 1.0}

MHYSER 1.0 is a quasi-steady model in which the water discharge hydrograph is approximated by bursts of constant discharge. MHYSER 1.0 performs basically five groups of operations which are attached to water phase, stream tubes, sediment phase, riverbank stability analysis and stream power minimization respectively.

MHYSER 1.0 uses the continuity equation and the energy equation, when there are no changes in the flow regime, while the momentum equation is used with the continuity equation when there are changes from supercritical to subcritical flows, or vice-versa. For backwater computations, the standard step method is used [6] and the friction losses are computed by a uniform flow formula as it is generally admitted [7]. Irregular cross-sections can be handled regardless of whether the river reach is of a single channel or multiple channels. For the latter case, the variables related to the cross-sectional geometry are computed for each sub-channel and are summed to obtain the total values. Moreover, internal conditions such as weirs, falls and sluices are modeled by rating curves.

After the backwater profiles are calculated, the cross sections are divided into sections of equal conveyance or stream tubes. These stream tubes are used as if they were conventional one-dimensional channels with known hydraulic properties, and sediment routing can be carried out within each stream tube almost as if they were independent channels. Once the top widths are determined, the velocities of the stream tubes are calculated giving a crosswise velocity distribution at every cross section.

Stream tube locations are allowed to vary with time. Therefore, although no material is allowed to cross stream tube boundaries during a time step, lateral movement of sediment is described by lateral variation of the stream tube boundaries. For bed load sediment transport, MHYSER 1.0 uses the transport functions of DuBoys [8], Meyer-Peter and Müller [9] and Parker [10]. For bed-material load, the used equations are: Laursen [11], Toffaleti [12], Engelund and Hansen [13], Ackers and White [14], Yang [15, 16, 17]. Both the space and temporal derivatives are approximated by first order finite difference operators [18]. Transport potential of cohesive sediments is computed using the approach of Partheniades [19] and Mehta et al. [20].

To compute the bed changes, the sediment transport is computed for each individual sediment size fraction within each stream tube. The bed changes are computed as a sum of the bed change for each particle size. To maintain numerical stability the time step is determined by a Courant-Friedrichs-Lewy (CFL) condition [21]. Since the kinematic wave speed of the bed changes is not easily quantified, numerical experimentation is required to determine suitable time step to be used for a simulation.

MHYSER 1.0 uses the method of Bennett and Nordin's method [22] for bed composition accounting procedure by dividing the bed into conceptual layers. The top layer, or active layer, contains the bed material available for transport. Beneath the active layer, the storage layer or inactive layer exists. Below these two layers there is the undisturbed bed. The active layer is the most important layer in this procedure. Erosion of a particular size class of bed material is limited by the amount of sediments of that size class presented in the active layer. At the end of each time step, bed material is calculated in each stream tube. At the beginning of the next time step, after the new locations of the stream tube boundaries are determined, these values are used to compute the new layer thickness and bed composition.

The determination of depth and width adjustments is based on the minimum stream power theory [23] which states that a river will minimize its stream power subject to hydrologic, hydraulic, sediment, geometric, geologic, and man-made constraints. Choosing the direction for channel adjustments is made by minimizing total stream power at different stations. If alteration of the channel widths results in lower total stream power than raising or lowering 
of the channel's bed, then channel adjustments progress in the lateral direction. Otherwise, the adjustments are made in the vertical direction.

\section{Application: the 1996 lake Ha!Ha! flood}

\subsection{Site description}

From July 18 to 21, 1996, unusually heavy rains affected the Saguenay region of Québec, Canada, between Lake St. Jean and the St. Lawrence River (figure 1). This led to widespread flooding and damage including the destruction of many run-of-the-river dams on rivers discharging into the Saguenay River and Saguenay Fjord and course adjustments of the rivers in the region. The most severely affected during the 1996 floods was the Ha! Ha! River. This river drains a catchment of $610 \mathrm{~km}^{2}$. The Ha! Ha! River links Lake Ha! Ha! to the Ha! Ha! Bay, an arm of the Saguenay Fjord.

The Ha! Ha! Lake is impounded by a concrete dam which suffered little damage during the flood. Lake breaching nevertheless occurred when a small earthen dyke situated to the south of the dam was overtopped by the rising water level. Incision of a new outlet channel resulted, bypassing the concrete dam and leading to rapid drainage of the main lake. Because of the incision, the lake level dropped from a level of $381 \mathrm{~m}$ to a new level of $370 \mathrm{~m}$ (average mean sea level). Brooks and Lawrence [24] give a detailed description of this flood and the corresponding damages. They estimate the peak outflow to be in the range $1080-1260 \mathrm{~m}^{3} / \mathrm{s}$ at a surveyed cross-section $27 \mathrm{~km}$ downstream of the dyke. In this paper, the study area extends from the dyke to the falls located $9.8 \mathrm{~km}$ downstream.

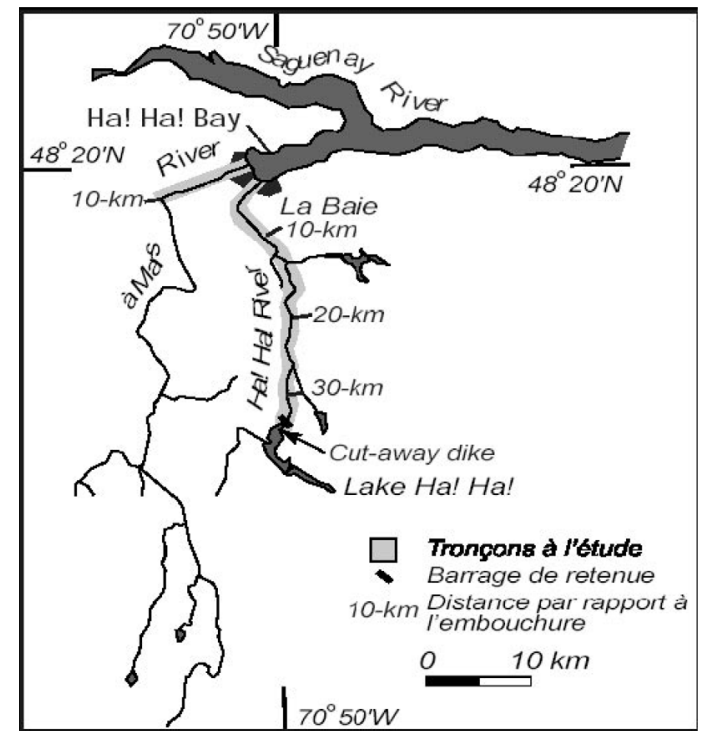

Fig. 1. Ha! Ha! River. [25]

\subsection{Input data}

The outflow discharge hydrograph (figure 2), the transversal cross sections and the sediment particle size distribution curve (figure 3 ) have been used by Mahdi and Marche [26]. For the simulations, a time step of 6 minutes and 98 transversal cross sections are used. 


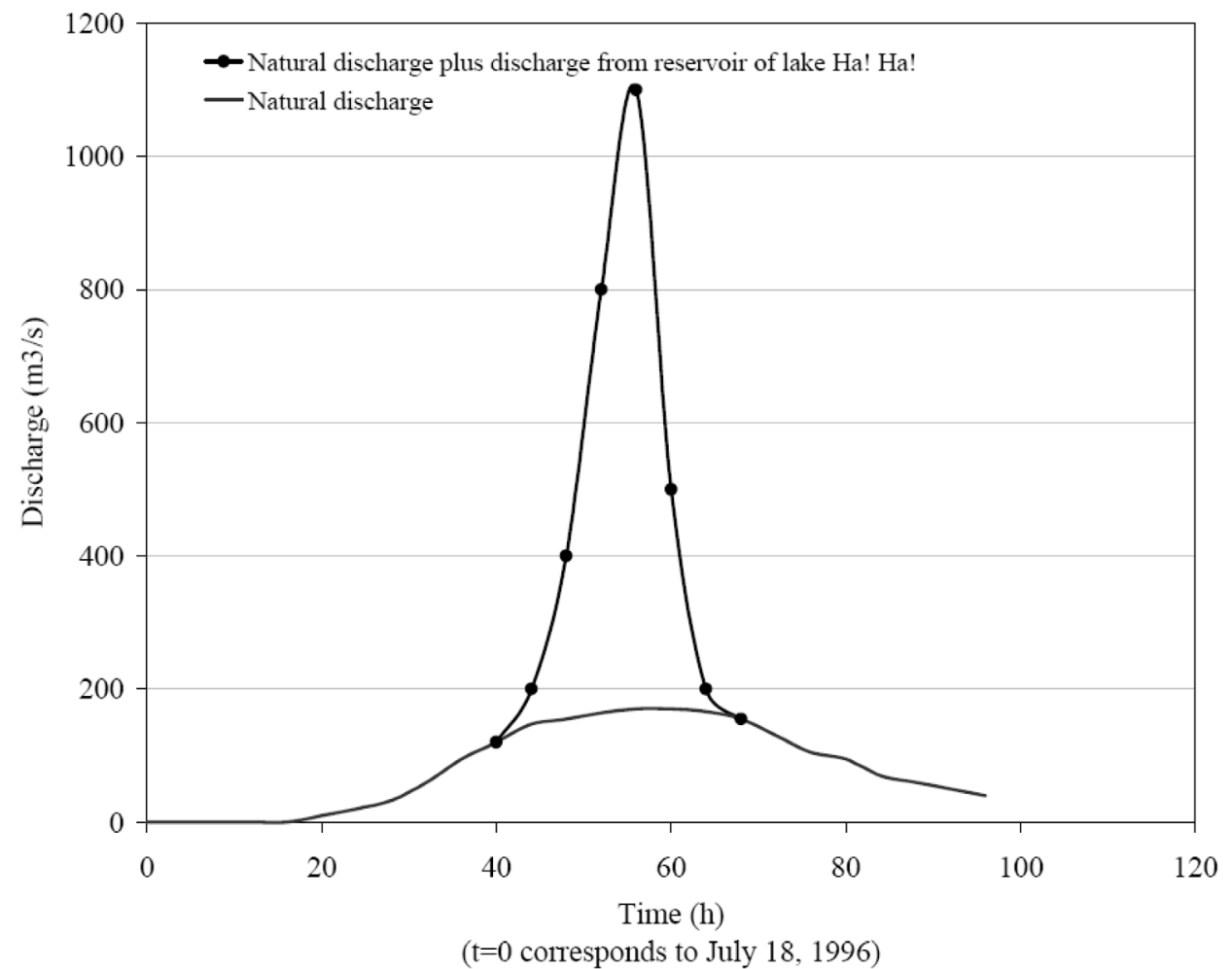

Fig. 2. Outflow discharge hydrograph.

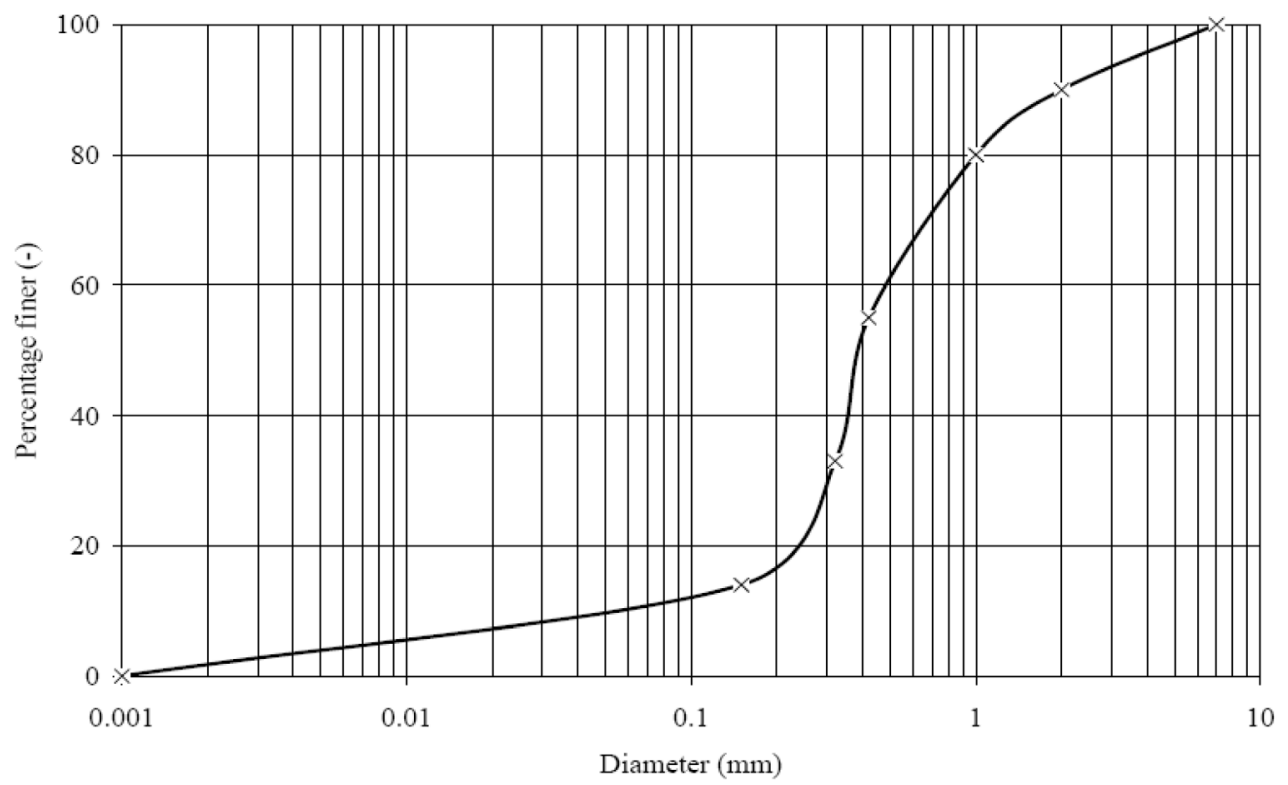

Fig. 3. Sediment particle size distribution used in the simulations. 


\subsection{Results}

\subsubsection{Longitudinal profile's evolution}

Figure 4 demonstrates the initial and final measured longitudinal profiles with the final simulated one. MHYSER 1.0 simulates well the erosion and deposition tendencies even if for the upstream cross sections, the predicted thalweg is $3 \mathrm{~m}(22 \%)$ deeper than the observed one. The erosion is overestimated, while the deposition is underestimated as shown in figure 4.

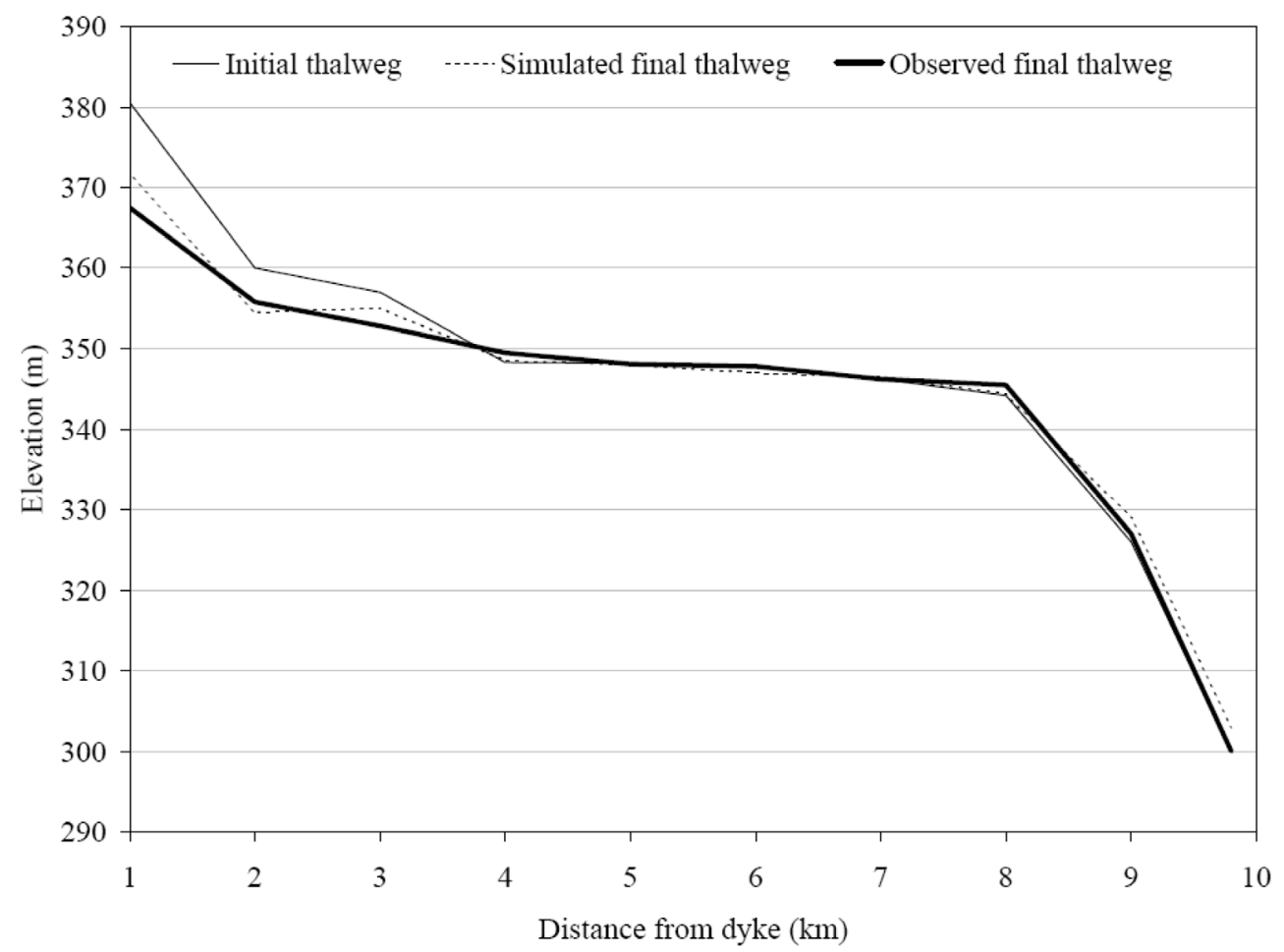

Fig. 4. Plot of the initial, final measured and simulated thalwegs.

\subsubsection{River banks' retreat}

Figure 5 shows the initial and final measured river's widths superposed to the final simulated ones. MHYSER 1.0 captures well the trend of riverbank's retreat. 


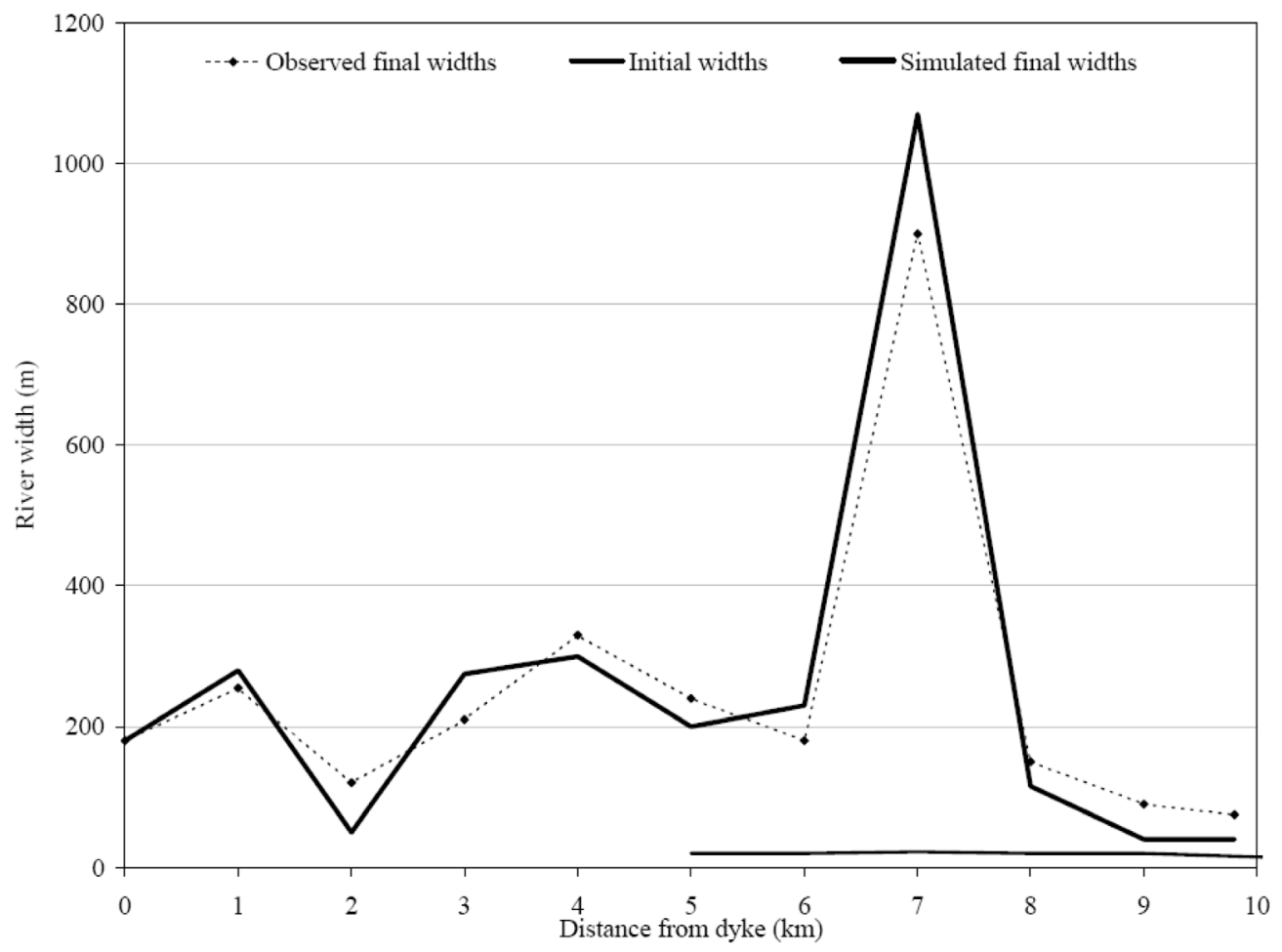

Fig. 5. Plot of the initial, final measured and simulated river widths.

\subsubsection{Cross-sections' evolution}

Figure 6 and 7 shows examples of simulated and measured cross-sections after the flood passage. Using MHYSER 1.0, some sections were well simulated but, others were not as illustrated by these figures. 


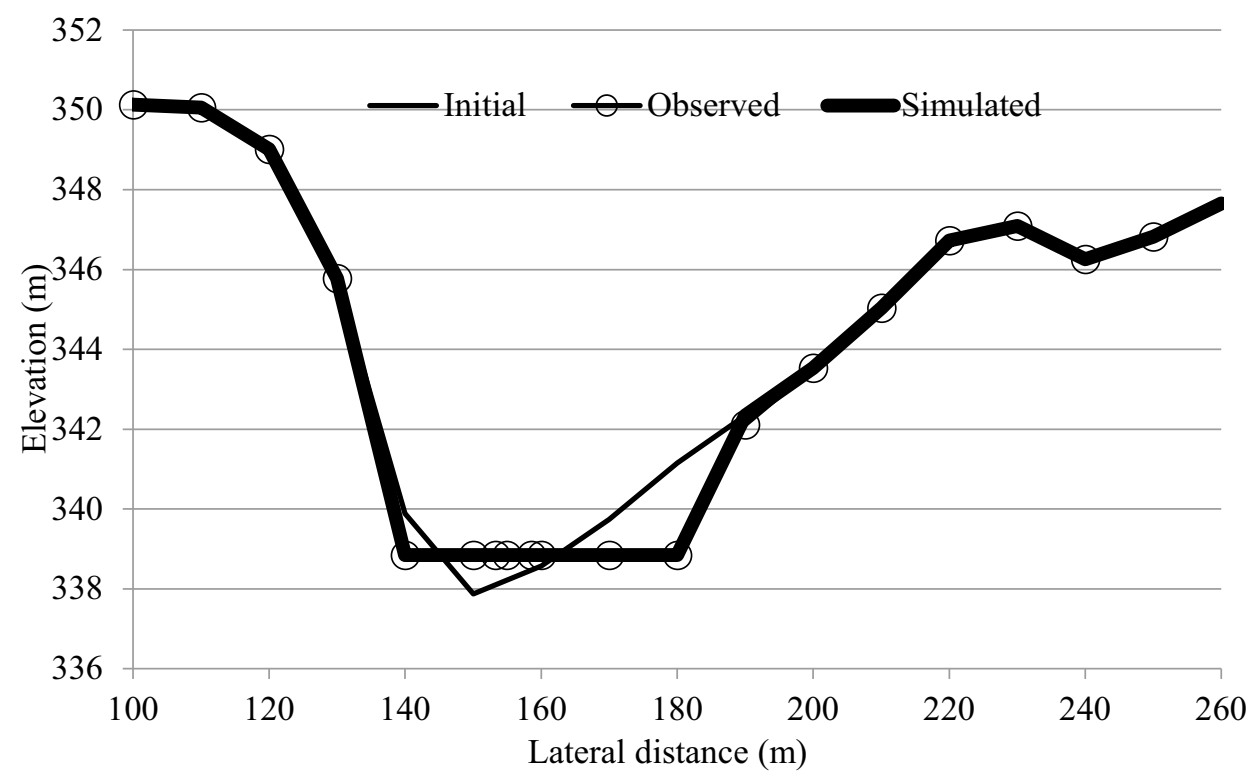

Fig. 6. Example of a good prediction of cross-section's evolution by MHYSER 1.0.

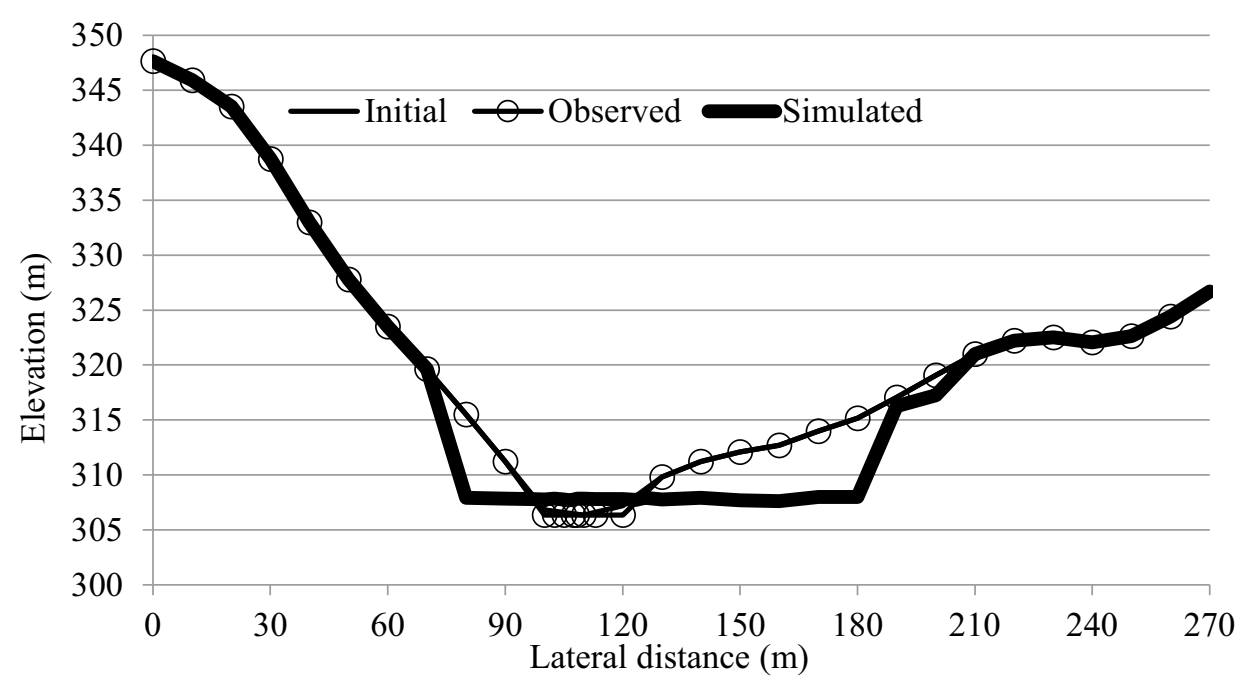

Fig. 7. Example of a poor prediction of cross-section's evolution by MHYSER 1.0.

\section{Conclusion}

Several river systems could suffer extensive catastrophic floods in the event of a dam break. This paper presents MHYSER 1.0, a semi-two-dimensional model, using the stream tubes concept to achieve lateral variations of velocity, flow stresses and sediment transport rate. Applied to the Ha! Ha! River (Quebec, Canada) during the 1996 "downpour", MHYSER 1.0 predicts well the river's changes. Please note that MHYSER1.0 cannot be used to predict exact changes of a river reach. MHYSER 1.0 is well suited to predict the evolution trend of 
a river reach undergoing a flood. This application shows the capabilities of this model and predicts its promising role in real engineering cases.

This research was supported in part by a National Science and Engineering Research Council (NSERC) Discovery Grant, application No: RGPIN-2016-06413.

\section{References}

1. M. Lapointe, S. Driscoll, N. Bergeron, Y. Secretan, M. Leclerc. Water Ress. Res. 34(9) 2383-2392 (1998)

2. T. Mahdi. Nat. Hazards 49(3) 590-603 (2009)

3. T. Mahdi. Nat. Hazards 49(3) 577-589 (2009)

4. T. Mahdi. Nat. Hazards 49(3) 565-576 (2009)

5. J. McKibbon, T. Mahdi. Nat. Hazards 54(3) 879-899 (2010)

6. F. M. Henderson. Open channel flow. MacMillan Book Company, NY (1966)

7. S. C. Jain Open channel flow. Wiley, Chichester (2000)

8. M. P. Du Boys. Annales des Ponts et Chaussées 18(5) 141-195 (1879)

9. E. Meyer-Peter, R. Müller. $2^{\text {nd }} I A H R$ Congress Stockholm, 39-64 (1948)

10. G. Parker. J. Hydr. Res. 28(4) 417-436 (1990)

11. E. Laursen. J. Hydr. Div. ASCE 84(HY1) 1-36 (1958)

12. F. Toffaleti. J. Hydr. Div. ASCE 95(HY1) 225-246 (1968)

13. F. Engelund, E. Hansen. A monograph on sediment transport in alluvial streams. Teknish Forlag, Technical Press, Copenhagen, Denmark (1972).

14. P. Ackers, W. White. J.Hydr. Div. ASCE 99(HY11) 2041-2060 (1973)

15. C. T. Yang. J.Hydr. Div. ASCE 99(HY10) 1679-1704 (1973)

16. C. T. Yang. J. Hydrology 40 123-138 (1979)

17. C. T. Yang. Div. ASCE 110(HY12) 1783-1797 (1984)

18. C. Hirsh. Numerical computation of internal and external flows: fundamentals of numerical discretization. John Wiley, NY (1990)

19. E. Partheniades. 3rd Int. Symp. River Sedimentation, Jackson, MS, 3-25 (1986)

20. A. J. Mehta, E. J. Hayter, W. R. Parker, R. B. Krone, A. M. Teeter. J. Hydr. Eng. ASCE 115(8) 1076-1093 (1989)

21. J. A. Cunge, F. M. Holly, A. Verwey. Practical aspects of computational river hydraulics. Pitman, London (1980)

22. J. Bennet, C. Nordin. Hydrological Sci. Bull. 22 555-569 (1977)

23. H. H. Chang, J. C. Hill. Applying Research to Hydraulic Practice. Proc. ASCE Hydr. Div. Conf. Ed. Peter E. Smith (1982)

24. G. R. Brooks, D. E. Lawrence. Geomorphology 28 141-168 (1999)

25. Couture, R. and Evans, S.G. 2000. Achievements and Prospects. Proc. 53rd Canadian Geotechnical Conference. Ed. Geological Survey Can., Ottawa, ON (2000)

26. T. Mahdi, C. Marche. Can. J. Civil Eng. 30 (3) 568-579 (2003) 